vitamin A, although it is not clear whether the compound occurs in the liver as such or arises as a transformation product of vitamin A during the saponification and isolation process. The work of Edisbury and co-workers ${ }^{5}$ on fish liver oils would suggest the latter may be the case.

Our concentrates were obtained by processes of solvent extraction, saponification, chromatographic adsorption and molecular distillation which will be described in detail elsewhere and which parallel quite closely those employed by Penn and Kaplan. The relationships between ultra-violet absorption spectra and fluorescence spectra are still not well understood; but the presence of fine structure in the near ultraviolet absorption of these fluorescing concentrates suggests the possibility that the banded fluorescent spectrum observed by Penn and Kaplan might have arisen from a similar substance.

The carcinogenic action of these liver extracts was negative when tested by subcutaneous injection in tricaprylin solution in mice. Since these extracts were essentially free from sterol, these observations do not contradict the findings of Hieger ${ }^{6}$ concerning the carcinogenic activity of cholesterol fractions from similar source material.

R. Norman Jones J. R. JAMIESON

Division of Chemistry,

National Research Council, Ottawa.

1 Penn and Kaplan, Nature, 160, 18 (1947).

' Jones and May, Cancer Res., 4, 304 (1944).

3 Zechmeister and Polgár, Science, 100, 317 (1944).

4 Shantz, Cawley and Embree, J. Amer. Chem. Soc., 65, 901 (1943).

5 Edisbury, Gillam, Heilbron and Morton, Biochem. J., 26, 1164 (1932).

- Hieger, Nature, 160, 270 (1947).

\section{Tensile Stress as a Factor in Fern Phyllotaxis}

Anatomical investigations of the development of leaf primordia in the broad shield fern (Dryopteris aristata Druce $)^{1,2}$ have led me to the view that during growth each primordium sets up tangential tensile stress in the apical meristem above its axil. A further hypothesis is that the next primordium to be formed arises in that region of the apical cone in which tensile stress is minimal. It has been observed that meristematic tissue in regions subjected to tensile stress typically develops into parenchyma.

In his "Allgemeine Morphologie der Gëwachse" (1868, p. 508), Hofmeister has advanced a hypothesis on the same general lines. He has suggested : (1) that the outer walls of the superficial cells of the shoot apex offer resistance to the lateral outgrowth of new organs (primordia); (2) that this resistance is not uniform over the growing point, new lateral organs appearing in regions of greatest elasticity; (3) that in proximity to the last formed primordia the superficial mombrane, being already stretched, has minimal elasticity; (4) that a now primordium will appear in that position on the apex which lies farthest from the last formed primordia, that is, in the position of maximal elasticity and minimal tension. While Hofmeister's observation that new leaf primordia arise in the largest gap has been accepted by many investigators of phyllotaxis, his mechanical theory outlined above has received little support.

Already Snow and Snow ${ }^{3,4}$ have shown that if the vegetative apex of several different flowering plants is incised, either transversely or longitudinally, the cuts typically gape. They have used this information

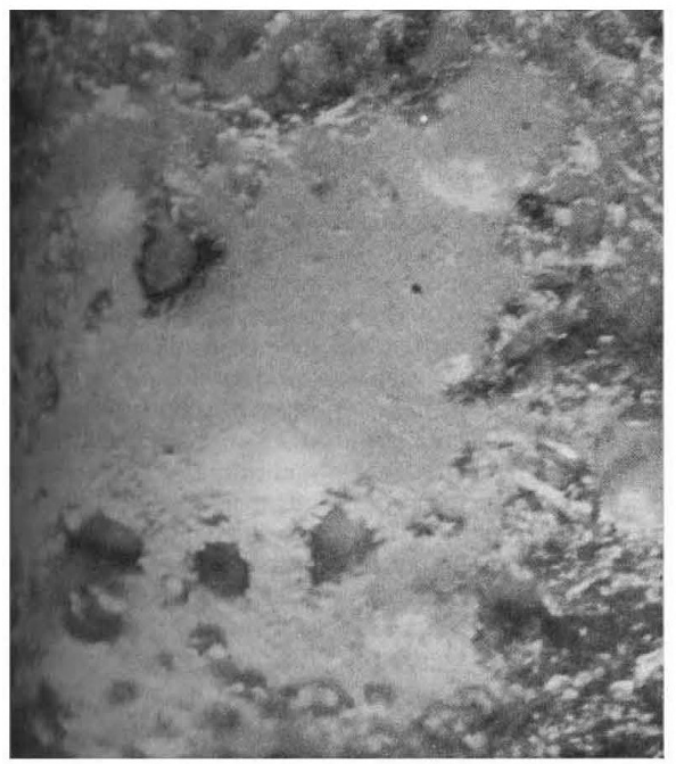

DOWNWARD VIRW OF THE SHOOT APEX OF Dryopteris aristata. THE CIRCULAR PUNCTURE (TOP CENTRE) IS IN THE POSITION OF THE NEXT LEAF PRIMORDIUM TO BE FORMED. THE PUNOTURI IN THE AXIIS OF THE PRIMORDIA (TOP LEFT AND RIGHT) ARE DISTENDED TANGENTIALLY, AS IS ALSO THAT OF THE PRTMORDTUM (BOTTOM RIGHT) BELOW. ( $\times 40)$ (PHOTO. BY ERNEST ASHBY)

to refute the view of Schuepp ${ }^{5,6}$ and Priestley ${ }^{7}$ that there is more rapid growth of the superficial than the internal tissue at the apex and hence that leaves arise as a result of compressive stress; but they have not directly suggested that the presence of tensile stress in the apical meristem may be a factor determining phyllotaxis (in conjunction with other factors).

Preliminary studies of the distribution of growth in $D$. aristata, in specimens in which the apical region had been covered with a thin layer of lamp-black (applied as a suspension in 10 per cent gum arabic), support the hypotheses now advanced. Furthermore, when apices were laid bare and incised or punctured in different regions, positive evidence was obtained of the existence of tensile stress in and above the axil of each primordium, whereas stress was slight or absent in those regions in which the now primordia would arise (see accompanying photograph). The largest unoccupied space on the apical cone above the level of the last formed primordium, which, as Snow and Snow have pointed out, is the position in which the next leaf primordium will arise, is also that region of the apical meristem in which tensile stress is minimal. Why the imposition of tensile stress should affect the further development of the distinctive meristematic tissue at the shoot apex of ferns as it does is still obscure. The problem is an interesting one: its solution may be of considerable importance to our knowledge of morphogenetic processes.

Department of Cryptogamic Botany,

C. W. WARDLAW

\section{The University,}

Manchester 13. Oct. 1 .

1 Wardlaw, C. W., Ann. Bot., N.S., 8, 387 (1944).

${ }^{2}$ Wardlaw, C. W., Ann. Bot., N.S., 9, 217 (1945).

${ }^{3}$ Snow, M., and Snow, R., Phil. Trans. Roy. Soc., B, 221, 1 (1931); 222, 353 (1933).

- Snow, M., and Snow, R., Exper. Biol. Symposium, Oxford, 1947.

5 Schuepp, O., Ber. deutsch. bot. Ges., 32, 328 (1014).

- Schuepp, O., Jb. wiss. Bot., 57, 17 (1916).

'Priestley, J. H., Biol. Rex., 3, 1 (1928). 